\title{
HOSPITAL-TO-HOME: A MODEL FOR TRANSITION OF CARE
}

Dr Fok Wai Yee Rose, Dr Low Sher Guan Luke, Dr Farhad Fakhrudin Vasanwala

\begin{abstract}
Singapore is among the fastest-aging countries in the world. By 2030, about one in every five residents would be 65 years or older and many of them may need long-term home care. Local studies have predicted a rise in disability rates as the population ages. To meet this need, our government has ramped up home care services to enable the elderly to "age in place" at home. In line with the Singapore Ministry of Health's vision of building sustainable healthcare and the initiative of "Beyond Hospital to Home", transitional care programmes in hospitals were renamed Hospital-to-Home in April 2017.
\end{abstract}

Under the programme, a comprehensive care plan is constructed to ensure safe and seamless transition from hospital to community settings. This requires the expertise of a multidisciplinary team to establish care needs as well as implement appropriate and cost-effective interventions to achieve positive outcomes. An enhanced nursing role, "Patient Navigator", was established to help navigate the transition of care beyond the usual nursing care needs that oversees coordination of care and social services.

Keywords: transitional care; long-term care; complex problems; preventive health; patient-centric; multidisciplinary team; community resources

SFP20 I 9; 45(3): 3 I -35

\section{INTRODUCTION}

The Hospital-to-Home $(\mathrm{H} 2 \mathrm{H})$ programme aims to help patients with multiple medical conditions by supporting the patient medically, functionally and psychosocially post-discharge. If needed, this programme will match and link patients to appropriate community services, to enable them to stay at home safely. This is in line with the Ministry of Health's (Singapore) vision of promoting patient-centric care through

\section{ROSE FOK WAI YEE}

Senior Resident Physician

Division of Medical Oncology, National Cancer Centre

Singapore

\section{LOW SHER GUAN LUKE}

Consultant

Department of Family Medicine, Sengkang Health

\section{FARHAD FAKHRUDIN VASANWALA}

Senior Consultant Family Physician

Medical Care, Institute of Mental Health integrated care services organised around the patient. Led by the Agency for Integrated Care, the programme pools together manpower resources by consolidating existing transitional care schemes run individually by hospitals and achieving a more structured workflow. In addition, funding for this programme is made more flexible and allows care providers to tailor services to each patient's specific needs. ${ }^{1}$ The majority of patients on this programme suffer from multiple comorbidities which include stroke, dementia, parkinsonism and cardiac failure.

The following case study illustrates how a $\mathrm{H} 2 \mathrm{H}$ team managed complex biopsychosocial issues in a systematic manner as well as accessed and coordinated community resources efficiently.

\section{CASE STUDY}

Madam $\mathrm{N}$ is an 87-year old female, with advanced dementia from Alzheimer's Disease (AD) and Behavioural and Psychological Symptoms of Dementia (BPSD) on a background of multiple chronic conditions. Pre-morbidly, she was home and chair-bound, requiring assistance for basic activities-of-daily-living (bathing and dressing) and instrumental activities-of-daily-living (shopping, housework, medication, finance and telephone use). Her primary caregiver is her foreign domestic helper. The author was part of the family medicine team providing transitional home care after her hospital admission for urinary tract infection (UTI).

\section{BACKGROUND}

Madam N has recurrent UTI with a background of bladder diverticula, $\mathrm{AD}$, primary angle-closure glaucoma, hypertension and hyperlipidaemia. Her cognitive impairment was assessed by a geriatrician and she was diagnosed to have $\mathrm{AD}$.

Madam N's baseline performance for the Mini-Mental State Examination (MMSE) was $17 / 30$ in July 2016, and gradually deteriorated to $11 / 30$ in February 2017, which was when she was referred to the geriatrician. Upon diagnosis in 2017 (which was a few years after the onset of cognitive impairment), Madam $\mathrm{N}$ was noted to have progressive short-term memory loss of insidious onset. Over the past few years, she slowly exhibited apraxia, requiring help with dressing and bathing. She developed delusion of her helper stealing things from her but was not verbally or physically aggressive towards her. While she had a jovial personality previously, she now experienced periods of low mood and insomnia. Gradually over time, she was unable to recognise her family members with advancing AD.

Madam $\mathrm{N}$ suffered recurrent constipation from poor oral intake and dehydration which resulted in recurrent UTI, further aggravating her physical distress and BPSD. The family was instructed on the management of constipation and offered pharmacological treatment for her AD and BPSD. However, they were not keen on medication for $\mathrm{AD}$ and decided to 
manage her conservatively in view of health beliefs, fearing that medication would cause dependency and addiction despite extensive explanation and counselling from our healthcare team. Nevertheless, the family agreed to put her on antipsychotics as they had difficulty managing her BPSD.

Her current medical issues are:

1. Advanced dementia with BPSD

2. Recurrent catheter-associated UTI on a background of bladder diverticula on follow up by the urologist

3. Sacral pressure injury on a background of immobility (detected at second home visit)

Other medical issues include hypertension and hyperlipidaemia (both on diet control) and acute angle glaucoma.

Her medications are:

\begin{tabular}{|l|l|}
\hline Name & Dosage \\
\hline Bisacodyl rectal suppository & $10 \mathrm{mg}$ ON prn \\
\hline Sennosides & $7.5 \mathrm{mg}$ ON \\
\hline Lactulose syrup & $10 \mathrm{mls}$ TDS \\
\hline Quetiapine & $6.25 \mathrm{mg} \mathrm{ON}$ \\
\hline Mirtazapine soltab & $7.5 \mathrm{mg} \mathrm{ON}$ \\
\hline Brinzolamide eyedrops 1\% & 1 drop to left eye \\
\hline Timolol \& travoprost eyedrops & 1 drop to left eye \\
\hline
\end{tabular}

\section{Pre-discharge assessment}

During the inpatient stay, the medical team managing Madam $\mathrm{N}$ educated her caregiver to monitor for signs of urine infection and constipation. She was then referred to the transitional home care programme prior to discharge and was evaluated by the $\mathrm{H} 2 \mathrm{H}$ team to have complex medical, nursing needs, functional issues and a plan was made based on her care needs and balancing caregivers' capability.

\section{First H2H visit}

\section{Problems of immobility}

Madam $\mathrm{N}$ experienced functional decline after the repeated hospitalizations. In the initial visit, caregivers were identified and educated on the complications of immobility like bed sores, deep vein thrombosis, pneumonia and contractures. They were taught how to perform two-hourly turning to reduce the likelihood of pressure sores and to prop the patient up for at least 30 minutes after feeds to diminish the risk of aspiration pneumonia. The physiotherapists and occupational therapists trained the caregivers to conduct a passive range of movements of the limbs to lessen contractures. To reduce constipation, the caregivers were instructed to ensure adequate hydration, prophylactic stool softeners, and to insert suppositories if there was no bowel movements for two days or more. To ensure adequate hydration, the family was instructed to have a food diary, schedule fluids and look out for signs of dehydration like hypotension, decreased urinary output and concentrated urine in the indwelling catheter (IDC) bag.
Figure I. Genogram of Madam N's family

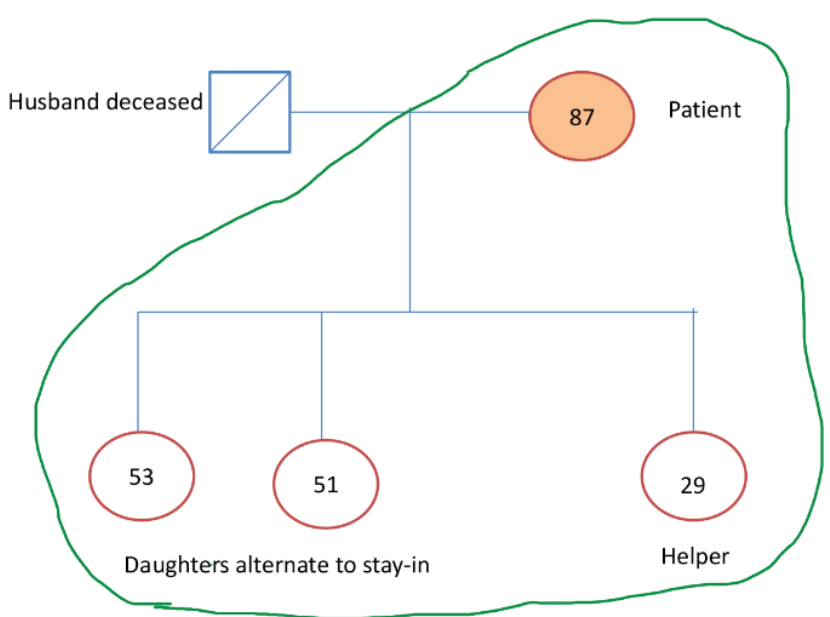

Supporting caregivers

Madam $\mathrm{N}$ lived in a three-room HDB flat with lift landing. Her domestic helper is a trained nurse from Myanmar and has worked for the family the past three and a half years. Her two daughters apportioned time during the week to look after their mother. The older daughter would come over to stay at Madam N's house on weekdays and her younger daughter would cover weekend duties. Although the arrangement was demanding in view of their own family needs, they persevered in their caregiving duties. Both daughters and helper were cognisant of the complications of immobility and were diligent in their care of the indwelling catheter (IDC), oral hygiene, blood pressure monitoring and skin care. However, they verbalised that they were only able to sponge the patient on her bed as they had difficulty transferring her to and from the bathroom. They admitted that they did not perform the two-hourly turning strictly at night as the procedure disrupted their sleep. However they tried their best to do this once or twice during the night.

\section{Second $\mathrm{H} 2 \mathrm{H}$ visit}

Frequent hospitalizations, functional decline and swallowing impairment.

Despite their dedicated care, Madam $\mathrm{N}$ developed multiple frequent febrile episodes due to UTI. Her recurrent UTI was assessed by the urologists. CT pyelogram and cystoscopy showed bladder wall thickening with diverticuli. In view of high post-void residual urine and failed intermittent catheterization, an IDC was recommended. Her caregivers found the intermittent catheterization challenging as the patient was uncooperative.

Even with the collaborative efforts between the inpatient and $\mathrm{H} 2 \mathrm{H}$ teams, her condition deteriorated and she started having swallowing difficulty. She was referred to the speech therapist who recommended diet modification, thickening of fluids, proper positioning of feeding alongside with other manoeuvres to avoid aspiration pneumonia. The family was offered nasogastric tube (NGT) feeding to allow the family to top up intake to maintain hydration and nutrition. Transitional 
feeding can be administered to allow the patient the pleasure of tasting her favourite food. In view of advancing dementia, the family chose to treat conservatively with diet modification and supportive care. The $\mathrm{H} 2 \mathrm{H}$ team visited the patient and caregivers during the hospitalisation to assess the caregivers' coping skills and any problems encountered.

\section{Caregiver stress}

A second home visit was initiated when Madam $\mathrm{N}$ became confused, and she was referred to the hospital and admitted for sepsis secondary to UTI. At the hospital, a sacral pressure injury was discovered a $5 \times 4 \mathrm{~cm}$ stage two sacral wound. The wound care nurse came on board to deslough and advise on wound care.

This hospitalisation coincided with the period that Madam N's helper was planning to return home after completion of her contract. The daughters tried to retain the helper but she wanted to return home, citing reasons of feeling burnt out and experiencing caregiver stress. The medical social worker (MSW) stepped in to help the family explore alternative care options. The family finally decided to employ a new helper with nursing or caregiving background, failing which they would consider the possibility of respite care in the interim while training their new helper. In addition, AD association has a caregiver support group which provides opportunity to meet other caregivers to share caregiving experiences and practical tips and discover resources together.

\section{Third $\mathrm{H} 2 \mathrm{H}$ visit}

A third visit was made six weeks after discharge to review the progress of the sacral pressure injury, which had worsened, despite the recommended caregiving and the availability of the hospital bed and air mattress prior to the pressure injury. Madam N's daughters and the new helper had difficulty adhering to the two-hourly turning and wound care. Madam N was admitted for inpatient desloughing by the surgeons, and upon discharge, the family opted on interim caregiver service while waiting for their new helper to be more trained in caregiver and nursing care. ${ }^{2}$

\section{BENEFITS OF MULTIDISCIPLINARY HOME CARE}

\section{Home Care - medical, nursing and allied health}

The $\mathrm{H} 2 \mathrm{H}$ team coordinated visits from the medical, nursing and allied health services and followed-up with regular phone calls. Our Patient Navigator (a senior staff nurse) provided nursing advice and care coordination. She also helped to manage the latex catheter during her visits and recommended the use of silicon catheter which would increase the interval of change. ${ }^{3}$ The wound nurse optimised wound care and the speech therapist ensured compliance with modification of diet and adequate nutrition. The MSW assessed for psychosocial needs and screened for caregiver stress.

In preparation for handover to the long-term home care team, St. Luke's Home Nursing was engaged early to look after the long-term IDC and wound care after discharge from the $\mathrm{H} 2 \mathrm{H}$ programme. ${ }^{4}$

\section{Medical equipment and transport}

The MSW helped Madam N to apply for the Senior Mobility Fund to purchase a hospital bed, air mattress. St Luke's Home Nursing applied for disposables (dressings, disposable diapers and catheters). A wheel chair and geriatric chair was previously obtained when she was more ambulant in 2017 upon diagnosis, when she had fair sitting balance and was able to pivot transfer with maximal assistance.

Dorcas escort service was engaged to ferry the patient to and from hospital outpatient appointments. ${ }^{5}$

\section{Financial assistance}

The MSW assisted Madam N in applying for Foreign Domestic Worker's (FDW) grant and lowered levy. In addition, she was eligible for the interim disability assistance programme for the elderly (IDAPE) which covered payments for medical, nursing as well as hiring FDW for the care of the disabled IDAPE claimant. $^{6}$

\section{CONTINUITY OF CARE}

\section{Transferring to long-term home care from $\mathrm{H} 2 \mathrm{H}$ programme}

Madam $\mathrm{N}$ was enrolled under the $\mathrm{H} 2 \mathrm{H}$ programme, initially targeted for three months but extended to the maximum allowable period of six months. When it was time to hand over to the long-term home care team (St. Luke's Home Nursing), the family was assured proper communication of medical history, care plans and goals of care. They understood the $\mathrm{H} 2 \mathrm{H}$ programme was a transitional care service targeted at empowering both patient and family for self-care. This was a daunting task for the family as they needed to build a fresh therapeutic relationship with the new healthcare team and at the same time, cope with their new helper. The $\mathrm{H} 2 \mathrm{H}$ team supported them during this challenging time via regular phone calls, providing a listening ear and useful advice to meet the care needs of the patient and family.

\section{Consolidation of medication, appointments \& preventive care}

The $\mathrm{H} 2 \mathrm{H}$ team discussed with relevant specialists to request for transfer of care with a plan to consolidate medical appointments. Unnecessary and expired medications were discarded. Madam $\mathrm{N}$ was given influenza and pneumococcal vaccinations during the last hospitalization.

\section{Advance Care Planning}

Madam N's family did not have the opportunity to discuss her values and preferences with regards to life-sustaining measures, Advance Medical Directive and Lasting Power of Attorney when she was more communicative. However after a family conference with the inpatient medical team during her hospitalisation, the family opted for comfort care and maximal ward management. This is a term used locally to denote fluids 
and antibiotics support but not for cardiopulmonary resuscitation, intubation and other extraordinary life-sustaining measures. Their preferred place of care was at home.

\section{DISCUSSION}

\section{Role of the Family Physician}

\section{Value of $\mathrm{H} 2 \mathrm{H}$ programme in transition of care}

Proper transition of hospital to long-term home care is critical to meet the needs of patients who face residual or new issues, both physical or psychosocial, after discharge from hospital.

In this case study, Madam N's declining health and increasing caregiver dependency and demands were significant challenges faced. The $\mathrm{H} 2 \mathrm{H}$ programme helped to address Madam N's medical needs to prevent recurrent UTI, sepsis and poor wound management. The programme also identified caregiver stress and promptly intervened to avoid a crisis.

The main value of the $\mathrm{H} 2 \mathrm{H}$ programme is to support the preferences of the family to care for the patient at home. This is made possible by accessing and coordinating the various community resources of home medical, home nursing, escort services and financial assistance.

\section{Supporting family in care navigation}

In the context of advanced dementia, the family physician's primary role is in supporting the family's navigation and coordination of care, and be thoroughly familiar with the various resources (individual, governmental and non-governmental) available to help the patient. With increasing longevity and the need to care for older persons at home, the family physician is best positioned to support this work from cradle to grave.

\section{Figure 2: Long Term Care in Singapore and its Challenges}

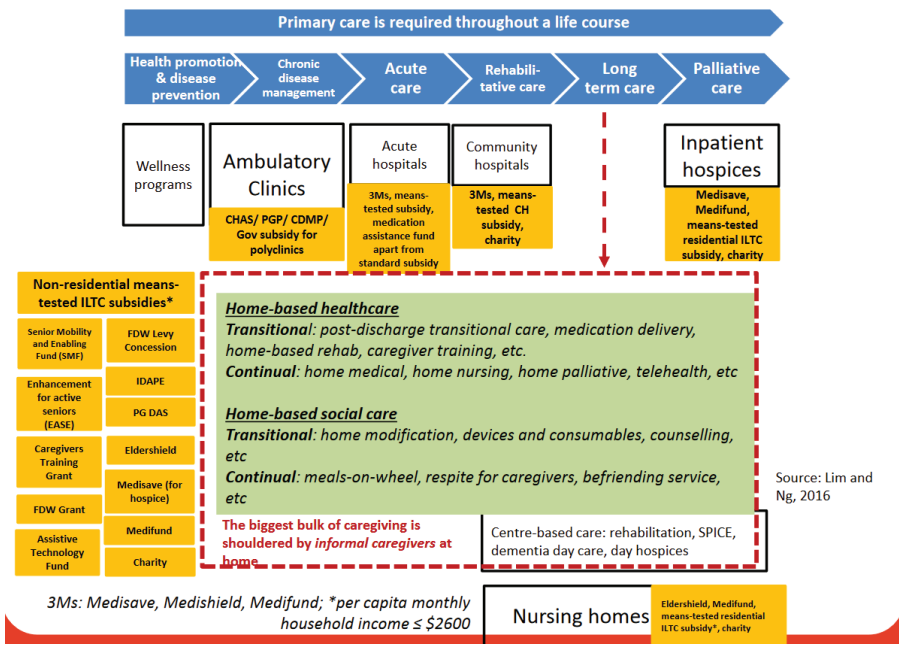

Source: Dr Ng Wai Chong (Tsao Foundation). Available from: https://www.ibf.org.sg/ event/Documents/Long\%20Term\%20Care\%20in\%20Singapore\%20and\%20its\%20Challenges.pdf
Even though the care plan is primarily for comfort care, certain treatable medical conditions like sepsis, UTI and infected bed sores should be promptly addressed. Timely intervention will help to manage reversible factors.

As community resources are expanding and the referral pathway may be complex, the role of the family physician is to ensure that the patient receives the appropriate care by accessing and linking up relevant resources.

\section{Comforter at the end of life}

In the spirit of the saying "to cure sometimes, to relieve often, and to comfort always", the family physician can initiate and support end-of-life care and convalescent care in consultation with the home hospice team.

When the patient decides not to pursue active treatment, the family physician should stand with the family to support them and walk the journey together.

\section{Home Care in Singapore}

A typical patient with multiple chronic medical problems can be managed well by a family physician with adequate community support and optimal utilisation of resources. ${ }^{7}$

Home care alleviates the issue of commuting, which may be a 'mammoth' task to immobile patients. At the same time, home visits give home care providers the opportunity to better understand how the patient and their caregivers are managing and coping at home. ${ }^{8}$

Availability of $\mathrm{H} 2 \mathrm{H}$ programme at restructured hospitals allows for timely discharge of these patients to their homes. A trained multidisciplinary team effort is required to ensure the integration of medical and social care services. The expertise and resources of transitional and long-term home care teams must continually be enhanced to manage increasing number of patients with complex medical problems. ${ }^{9}$

\section{CONCLUSION}

With the government's commitment towards preventive, primary and community care, we are now able to support our patients to manage their medical conditions better in the community. Transitional programmes like the $\mathrm{H} 2 \mathrm{H}$ programme help to identify patients who need help managing their conditions at home. The family physician is in a good position to provide continuity of care and coordinate resources in the home care setting. We believe that this patient centric care will result in improved patient satisfaction and positive health outcomes.

\section{REFERENCES}

I. Choo F. Hospital-to-Home programme has helped around 8,000 patients. The Straits Times. [newspaper on the Internet] 2 Feb 2018. [accessed 9 Mar 2019] Available from: https://www.straitstimes.com/singapore/health/public-hospital-transitiona l-care-programme-has-helped-around-8000-patients 
2. Ministry of Health. Service Requirements for Interim Caregiver Service. Singapore. [accessed 9 March 2019] Available from:

https://www.moh.gov.sg/docs/librariesprovider5/resources-statistics/guid elines/ics-requirements_16-aug_(website).pdf

3. Choo F. More help to come for patients transitioning from hospital to home. The Straits Times. [newspaper on the Internet] Jun 272017.

[accessed 9 Mar 2019] Available from:

https://www.straitstimes.com/singapore/health/more-help-to-come-for-p atients-transitioning-from-hospital-to-home

4. St Luke's. Our Services. [Internet] Singapore. [accessed 9 Mar 2019] Available from: https://www.slec.org.sg/our-services/?service= homenursing

5. Presbyterian Community Services. DORCAS Home care service. [Internet] Singapore. [accessed 9 Mar 2019] Available

from:http://www.pcs.org.sg/services/seniors-services/dorcas-home-careservice/?doing_wP_cron=|538|42005.69863200 | $87683 \mid 0546875$

6. Ministry of Health. Interim Disability Assistance Scheme for the Elderly (IDAPE). [Internet] Singapore. [updated: 12 July 2019; accessed 9 Mar 2019] Available from:

https://www.moh.gov.sg/cost-financing/healthcare-schemes-subsidies/inte rim-disability-assistance-programme-for-the-elderly

7. Vasanwala F. Working in Multidisciplinary teams for the Family Physician. The Singapore Family Physician. 2016 Oct I;42(4):34-8. 8. Low SG, Ng LC, Tan JS, Vasanwala FF. How to care for homebound patients? Proceedings of Singapore Healthcare. 2016 Sep;25(3): I8I-4.

9. Low LL, Tan AK, Vasanwala FF. Collaboration between two restructured hospitals' family physician-led transitional home care teams in the provision of home ventilation respiratory support. Proceedings of Singapore Healthcare. 2014;23(2): I73-6. 